\title{
Research and implementation of comprehensive analysis system of economic operation in tobacco industry
}

\author{
Ji Qi ${ }^{1, a^{*}, Q i a n ~ J i e, S h e n ~ C h a o, L u ~ H a i l o n g ~ a n d ~ Z h a n g ~ M i n ~}$ \\ ${ }^{1}$ China Tobacco Zhejiang Industrial CO.,LTD.,Hangzhou China \\ a19118112@qq.com
}

Keywords: comprehensive analysis system; multi-dimensional analysis; tobacco industry.

\begin{abstract}
Based on economic statistics, survey and the requirements analysis of tobacco industry, using information network and basic data platform and the establishment of special monitoring indicators, China Tobacco Zhejiang Industrial CO., LTD. implement a comprehensive analysis system about economic operation in the tobacco industry, which can provide a multi-dimensional analysis about the production, sales, inventory and benefit of cigarette brands in China, and provide a comprehensive, integrated information for all levels of management, which can improve the efficiency of decision-making, ability and accuracy.
\end{abstract}

\section{Introduction}

As a method of economic management, economic operation analysis is very important in the enterprise management, because it is not only involved in business management, but also objectively reflect the economic activities of enterprises, and help to improve the economic benefits of enterprises [1]. The economic operation analysis of enterprise has become an important basis of decision-making for the management of tobacco industry [2]. This requires the tobacco enterprises to scientific use economic operation analysis from all aspects and multi angle, summarize the experience in the practical work, draw lessons from history, expose the various kinds of the enterprise existence, so that the economic operation analysis of the enterprise can help to make the management and decision-making.

The enterprise comprehensive analysis system of economic operation collects the information of characteristics about enterprise economic development and use some analysis methods to analyse the current situation and development trend of enterprise management.

To carry out systematic and comprehensive economic analysis, realize the scientific and economic development and management of tobacco industry, China Tobacco Zhejiang Industrial CO., LTD. construct a comprehensive analysis system about the tobacco industry economic operation, which is based on the principle and analysis of micro economic, combining the characteristics of tobacco industry and China Tobacco Zhejiang Industrial CO., LTD., refining the indicators that can reflect the information of the management features. The system can dynamically reflect the operating status of the enterprise to service decision making. What's more, combined with the macroeconomic evaluation and analysis of the superior departments in charge of the industry, it can reflect the development of the industry economy and the implementation of the development plan in real time, and then provide decision support for the development and adjustment of the development strategy.

This paper mainly introduces the comprehensive analysis system of economic operation in tobacco industry. Through RFID public information service platform, information network and basic data platform, special monitoring indicators are established, a strategic and tactical deployment of the macro monitoring system is implemented, which can analyze the overall competitive advantage of the whole industry and help to focus on major brands and lead enterprises in the competitive ability and profitability, market influence, in order to help achieve brand strategy 


\section{Requirements analysis and key technologies}

\section{System Requirements Analysis}

The purpose of the comprehensive economic operation analysis system for China Tobacco Zhejiang Industrial CO., LTD.is to use the advanced information technologies and models, through combining the original marketing information systems and other relevant application systems, integrating industry economy basic databases and data models and indicator system,analyzing tobacco industry's management ,competition pattern, company sales and production, financial position, material management, etc., to provide a scientific and advanced analysis tool, which can carry out comprehensive economic operation analysis and monitoring, improve the transmission speed of tobacco industry economic information and the market reaction ability. To achieve speed, brand, scale, joint and industrial layout of the economy, improve the overall competitiveness of the industry and the real-time diagnostic data, provide information technology support for leadership decision-making.

Multi-dimensional analysis about the cigarette brand production, sales, inventory, and benefit through information technology is very important, which can help to grasp the overall situation of tobacco industry, deeply analyze specific individual enterprises, grasp the comparison with competitors, and give a clear and appropriate location for China Tobacco Zhejiang Industrial CO., LTD. and LiQun brand.This system is divided into five parts from the perspective of the industry, as shown in Figure 1:

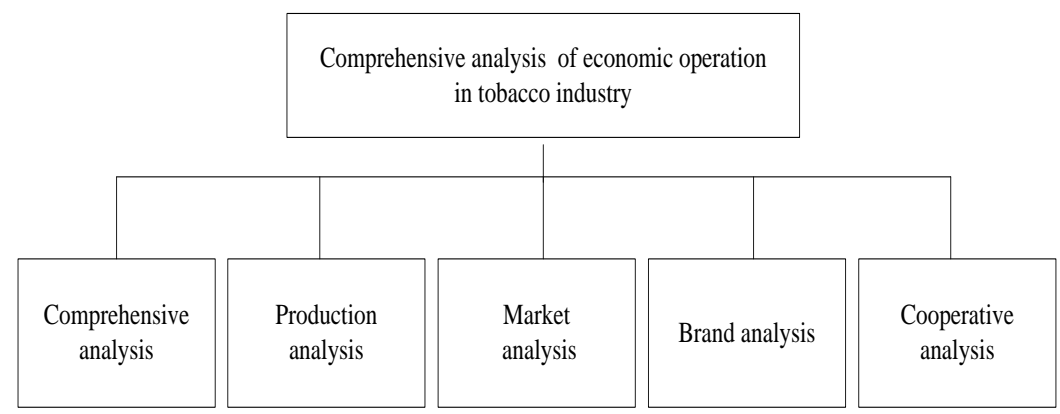

Fig. 1. comprehensive analysis content structure in Tobacco industry

\section{Comprehensive analysis}

The analysis content of this part includes production, sales, finance and other indicators, the analysis objects are all provinces to the cities, the analysis properties include the allocation price, wholesale price, retail price, tar content, price, and other properties;

\section{Production analysis}

From the perspective of production, this part analyzes 19 industrial self-produced domestic, export and co-production, and compare the industrial production schedule and various industrial development speed;

\section{Market analysis}

From the perspective of market analysis,this part analyzes the market share and competitive landscape of the tobacco, looking for opportunities;

\section{Brand analysis}

The scale and value of the brand will constitute the core indicators to reflect the brand market competitiveness, this part analyzes the influence of the leading brands, focuses on the positioning of the new products and the development of the product;

\section{Cooperative analysis}

This part focuses on regional layout, structure layout (single box taxes) and the arrival of co-production.

\section{Key Technologies}

The economic operation system needs to collect, filter, analyze, transmit, comprehensive utilization of all the data related to the enterprise, so that data can be converted into information and 
knowledge [4]. Advanced data warehouse (DW), OLAP and data mining technology are used as the core technologies. The system architecture diagram is shown in figure 2.

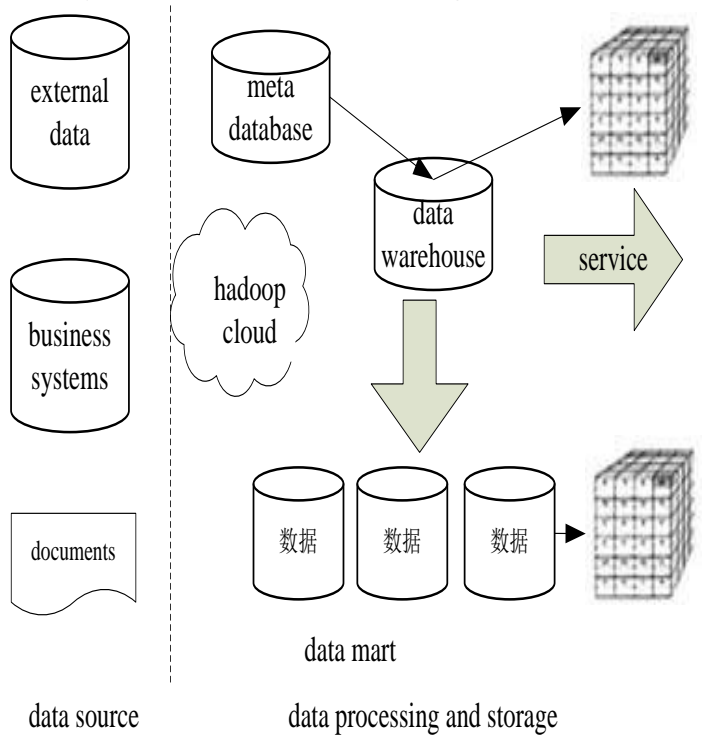

Fig 2. system architecture diagram

The data source of the whole system includes the enterprise internal data and external data, internal data mainly from ERP system, marketing system and all kinds of document information, external data mainly from the project data.

Based on data source, the business data is organized to form a data mart, and the physical storage structure is determined, and the corresponding meta data (including data dictionary, the definition of recording system, data transformation rules, data automatic loading frequency and business rules, etc.) is formed, and finally a data warehouse if formed according to "star architecture" (fact sheet + dimension tables). The analysis data needs to be rebuilt in accordance with multidimensional data model in order to form a multi - dimensional data cube structure to support the user 's multi-level analysis of data. Data in the data cube after processing, multi-dimensional display can be shown to the user. [5-7]

Front display and application mean using various data analysis tools, reporting tools, query tools, data mining tools to generate data report, analysis report and chart results.

\section{System Functions and Implementation}

\section{Comprehensive analysis}

This module focuses on the analysis of the whole situation of the tobacco industry,the status of China Tobacco Zhejiang Industrial CO.,LTD. in the industry, self-produced production, industrial sales, total benefits, taxes and profits of a single box, ranking about cost of a single box in nineteen cigarettes enterprises.specific functions include:

- Comparison of the sales ranking, the proportion and the development speed of the industry;

- Analysis of commercial sales structure of the industry;

- Comparative analysis of the benefits of the industry;

- Click on one of them, and the whole situation of the enterprise is displayed.

Analysis of the current period and the same period in the various industries of industrial output, commercial sales and gross profit and ranking, which can be sorted according to different indicators. Analysis indicators:

Industrial output (output of current period ; output of the same period; current ranking; ranking lift; increment; incremental ranking;increase amplitude; increase amplitude ranking; proportion; proportion ranking; co-production; co-production ranking; self-production yield; self-production yield ranking); 
Commercial sales volume(commercial sales volume of current period; commercial sales volume of the same period;current ranking; ranking lift;increment; incremental ranking;increase amplitude; increase amplitude ranking; proportion; proportion ranking);

Commercial sales amount (commercial sales amount of current period; commercial sales amount of the same period;current ranking; ranking lift;increment; incremental ranking;increase amplitude ; increase amplitude ranking; proportion; proportion ranking);

Gross profit(gross profit of one box; commercial gross profit; commercial gross profit of the same period; ranking; ranking lift; increment; incremental ranking; increase amplitude; increase amplitude ranking);

Analysis dimension: time(granularity size: month), cigarette(granularity size: industrial enterprise, brand, specification),business companies: (granularity size: city);

\section{Production analysis}

The module with the theme of production of industrial enterprises, analyzes its own brand, co-production, production scale and pace of development of the export of cigarettes to monitor the progress of production of industrial enterprises, as well as attention to the pattern of planned resources and trend analysis of production and sales of various indicators.Specific content includes:

comprehensive analysis of production, production schedule analysis, resource comparative analysis, production structure analysis, trend analysis.

\section{comprehensive analysis of production}

Analysis of different caliber of various industrial output of tobacco in the current period and the same period . By total production (total, self-produced total) own brand (domestic sales, export, co-production (the output side of storage volume) co-production (input side yield) yield of sample and other indicators to reflect the comprehensive situation of production.

\section{production schedule analysis}

Analysis of the production schedules and co-production schedule of various industrial output of tobacco. Indicators include the issue of cumulative production, cumulative production in the same period, the increment, the proportion of the current period, the proportion of the same period ,the proportion of incremental, production rankings, of the current period, production schedule, production schedule rankings and other indicators. The results can be shown in two ways :reports and graphs.

\section{resource comparative analysis}

Analysis of various industrial output of tobacco this year and an annual comparison of the various indicators. Indicators include output, production of its own brand, accounting for the proportion of industry output, co-production output, its own brand sales, The proportion of industry, plans to market support, ranking; The results can be shown in two ways :reports and graphs.

\section{production structure analysis}

Analysis of the brand and price category production structure of single-family tobacco, and which can be drilled down to size. Analysis of indicators include: total output, domestic production, export production, co-production. As shown in Figure 3. 


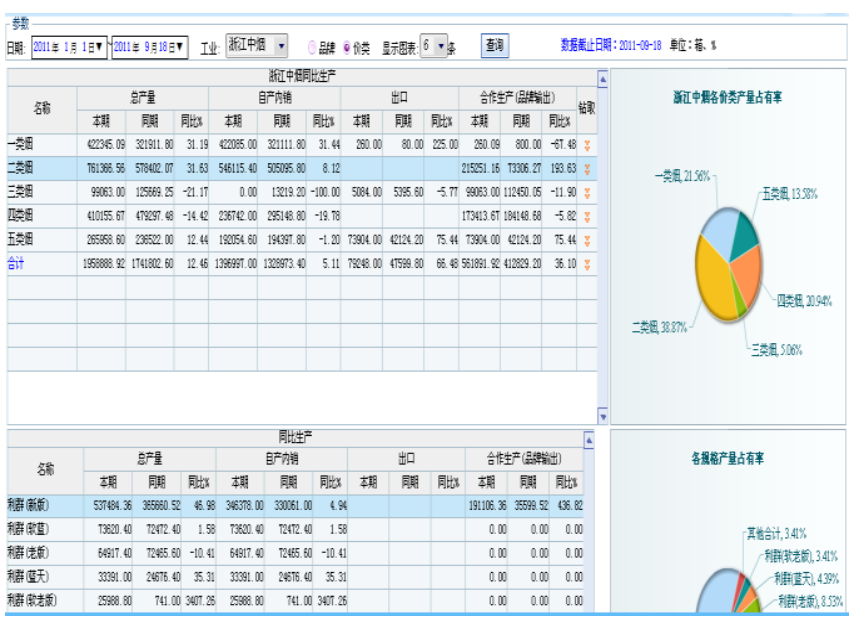

Fig. 3.production structure analysis

\section{trend analysis}

Monthly Report can show the monthly sales and inventory situation. Analysis indicators include: production (including exports), co-production (the output side of storage volume), industrial sales, industrial ending stocks, commercial sales volume, commercial sales amount, sales of single box.

\section{Market analysis}

The purpose of market analysis of the enterprises is to scientific summary and analyze all kinds of business information in a timely manner, to help move up the sales structure, guide consumption; through market analysis, real, comprehensive and accurate basis for the leadership decision analysis is provided and beneficial to control market and increase sales. The module provides market analysis include:

Market comprehensive analysis: set up the model of map analysis , combined with the map image to show sales in each market;

Competitive landscape analysis: view market distribution pattern from the angle of industry and cigarette ;

Supplier contribution analysis: view Supplier of qualifying from the angle of business.

Price analysis (by industry): analysis of sales structure by industry.

Price analysis (by business): analysis of sales structure by business .

For example, in price analysis (by industry), the system is shown in Figure 4 .

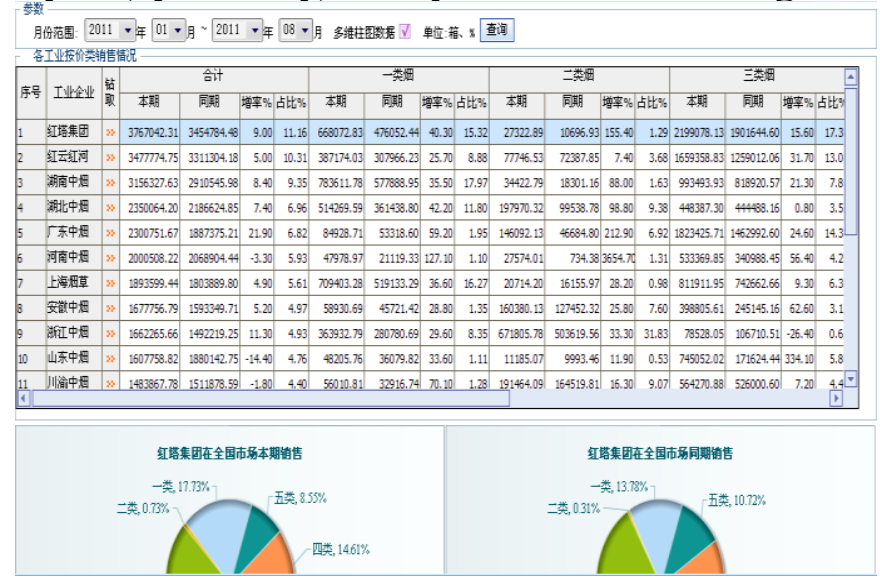

Fig. 4.Price analysis (by industry)

\section{Brand analysis}

This module is the analysis of the leading brand influence. It is divided into five small modules: 


\section{Analysis of key brands}

Analysis of the distribution of brands in the country, and it can be drilled down to the provinces. Analysis indicators: business sales in the current period, sales in the same period, increment ,amplitude, industrial sales, business sales, business gross profit, market share, share rankings.

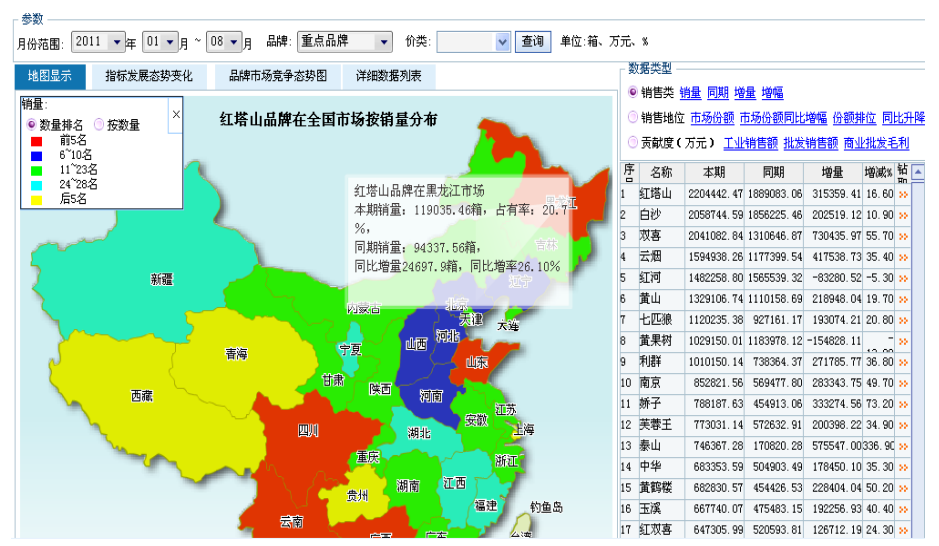

Fig.5. Analysis of key brands

\section{Brand summary analysis}

Analysis of the total sales of the brand and ranking. Analysis indicators: industrial production, commercial sales volume, commercial sales amount, sales of single box.

\section{Brand Price class analysis}

Analysis of total sales conditions and ranking each brand. Analysis indicators: industrial production, commercial sales volume, commercial sales amount, sales of single box.

\section{Double low Product Analysis}

Analysis of the market sales of double-low brand and product. Analysis indicators: industrial production, commercial sales volume, commercial sales amount, sales of single box.

\section{New brand inquiry}

Inquiry a new brand product detail for a period of time and double click the new brand it can display the brand sales trends. Query parameters: time, cigarettes, whether double-low.

New brand trend analysis

Analysis of the brand sales volume and amount within a month period; Analysis indicators: business sales volume, commercial sales amount.

\section{Cooperative analysis}

The module is mainly used to analyze which brand, category, quality, variety input to which tobacco factory, under construction strengthened to enable it to undertake the company and co-production of the big brands, which brings more benefit to the enterprise. According to the brand export and input enterprise, the brand co-production situation can be analyzed. In accordance with the export enterprise analysis, for example, analysis indicators include: the output side of storage capacity, input side output, the input side of a library volume, single-box sales. As shown in Figure 6.

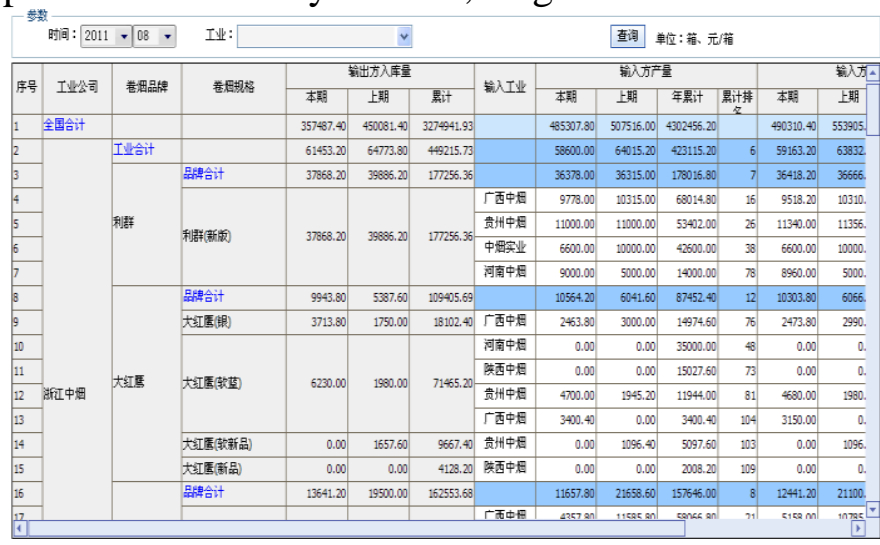


Fig. 6. Cooperative analysis

\section{Conclusion}

China Tobacco Zhejiang Industrial CO.,LTD. implements a comprehensive analysis system about the tobacco industry economic operation, combining the characteristics of tobacco industry. The system can collect, filter, analyze, transmit, comprehensive utilization of all the data related to the enterprise through advanced data warehouse (DW),OLAP and data mining technology, and provide a multi-dimensional analysis of the production, sales, inventory and benefit of cigarette brands in China, and provide a comprehensive, integrated information for all levels of management, which can improve the efficiency, ability and accuracy of decision-making to help achieve brand strategy.

\section{References}

[1] M. Xiang, The design and the use for the system of the modern enterprise's economical analysis. Shanghai Jiao Tong University.2000.

[2] X.H. He, Discussion on the economic operation of tobacco enterprises. Journal of Science and Technology Information of China.04 2012.

[3] Y. Zhang, Analysis and design of Yunnan tobacco economic operation system. Yun Nan University .2005.

[4] Y. Zhu, Construction of Tobacco company decision-making analysis system based on data-center.Computer and Modernization. vol.9,pp.23-26, 2009.

[5] X. Liu,L.L. He, J.H.Zheng,Tobacco business intelligence research in cloud environment. Industrial Control Computer,vol.25,pp.114-115,2012.

[6] X.W. Zhang, C.H. Li,X.Z. Qin, Research and initial implementation of large-scale data processing based on cloud computing. New Technology of Library and Information Service,vol. 27,pp.17-23,2011.

[7] G.H. Zhao,Decision-making research based on OLAP analysis model of multidimensional data.Inner Mongolia University of Technology,2006 